\title{
LIQUEN PLANO AMPOLLOSO EN LA EDAD PEDIÁTRICA, UNA ADECUADA RESPUESTA AL TRATAMIENTO CON ESTEROIDE ORAL
}

\author{
Solórzano Andrea ${ }^{1}$, Macías María $A^{2}$, Carrillo María $C^{3}$ \\ ${ }^{1}$ Residente de Dermatología, Facultad de Medicina, Universidad CES. Medellín, Colombia. \\ Centro Dermatológico Federico Lleras Acosta E.S.E. Bogotá, D.C., Colombia. \\ ${ }^{2}$ Pediatra. Dermatóloga pediatra, Centro Dermatológico Federico Lleras Acosta E.S.E. \\ Bogotá, D.C., Colombia. Instructora, Facultad de Medicina, Universidad CES, Medellín, Colombia. \\ ${ }^{3}$ Patóloga, Centro Dermatológico Federico Lleras Acosta E.S.E. Bogotá, D.C., Colombia. Instructora, \\ Facultad de Medicina, Universidad CES, Medellín, Colombia. \\ Correspondencia: andreasol82@hotmail.com \\ Recibido: Agosto 29 de 2013 Aceptado: Noviembre 12 de 2013
}

\begin{abstract}
Resumen
El liquen plano es una erupción pápulo-escamosa de la cual se han descrito numerosas variantes en su presentación clínica. Una de esas variantes es el liquen plano ampolloso, en la que se desarrollan vesículas y ampollas que se originan de las pápulas características del liquen plano, o rara vez, de piel de aspecto normal. Debido a la formación de ampollas, el diagnóstico diferencial incluye liquen plano penfigoide, penfigoide ampolloso, pénfigo vulgar, eritema multiforme e infección por virus del herpes, por lo tanto, el examen histopatológico es útil para el diagnóstico definitivo. Las opciones de tratamiento incluyen esteroides tópicos y sistémicos, retinoides sistémicos, fototerapia, antimaláricos y agentes inmunosupresores. Se presenta el caso de una niña con diagnóstico clínico de liquen plano ampolloso que fue confirmado por histopatología, destacando la importancia de conocer esta rara variante y demostrando la adecuada respuesta al tratamiento con esteroides orales.
\end{abstract}

Palabras clave: Liquen plano, ampollas, esteroides.

\section{BULLOUS LICHEN PLANUS IN CHILDREN, AN ADEQUATE RESPONSE TO TREATMENT WITH ORAL STEROID}

\begin{abstract}
Abstrac
Lichen planus is a papulosquamous eruption whith numerous clinical variants. One of these variants is bullous lichen planus in which vesicles and blisters develop originating from lichen planus papules, or rarely in normal-looking skin. Due to formation of blisters, differential diagnosis includes lichen planuspemphigoid, bullous pemphigoid, pemphigus vulgaris, erythema multiforme and herpes virus infection, therefore histopathological examination is essential for a definitive diagnosis. Teatment includes topical and systemic steroids, systemic retinoids, phototherapy, antimalarials and immunosuppressive agents. We report the case of a child with clinical diagnosis of bullous lichen planus confirmed by histopathology,emphazise the importance of this rare variant and demonstrating the adequate response to treatment with oral steroid.
\end{abstract}

Keywords: Lichen planus, blisters, steroid. 


\title{
LIQUEN PLANO BOLHOSO NA IDADE PEDIÁTRICA RESPOSTA ADEQUADA AO TRATAMENTO COM ESTERÓIDES POR VIA ORAL
}

\begin{abstract}
Resumo
O líquen plano é uma erupção papulo-escamosa com numerosas variantes em sua apresentação clinica. Dessas variantes clínicas, uma é o líquen plano bolhoso, onde vesículas e bolhas originam-se das papulas características do líquen plano, ou raramente, na pele de aparência normal. Devido à formação de bolhas, o diagnóstico diferencial inclui líquen plano penfigóide, penfigoide bolhoso, pênfigo vulgar, eritema multiforme e infecção pelo vírus do herpes, por isso, o exame histopatológico é útil para o diagnóstico definitivo. As opções de tratamento incluem esteróides tópicos e sistêmicos, retinóides sistêmicos, fototerapia, antimaláricos e imunossupressores. O caso de uma criança com diagnóstico clínico de líquen plano bolhoso foi confirmado por histopatológia , é apresentado com destaque para a importância de conhecer esta variante rara e demonstrando resposta adequada ao tratamento com esteróides orais .
\end{abstract}

Palavras-chave: Líquen, bolhas, esteróides.

\section{Introducción}

El liquen plano es una enfermedad inflamatoria idiopática mediada por linfocitos $\mathrm{T}$. Una de sus múltiples variantes es la forma ampollar o bulosa, que se caracteriza por la presencia de ampollas sobre las lesiones clínicamente características de la enfermedad.

\section{Caso clínico}

Se trata de una niña de 8 años de edad con lesiones permanentes, pruriginosas, generalizadas, de un mes de evolución, que iniciaron como "vejigas" en el abdomen, con posterior extensión a otras zonas, para lo cual le habían aplicado productos naturistas, con exacerbación de las mismas. También había sido medicada con betametasona tópica, dicloxacilina y loratadina oral, sin mejoría. La familia negó antecedentes de ingestión de medicamentos.

Al examen físico en tórax anterior y posterior, abdomen, glúteos, miembros superiores e inferiores se observaron múltiples placas eritemato-violáceas, descamativas, confluentes, con excoriaciones y costras hemáticas (Figura 1). Además, en los antebrazos, los muslos y las piernas varias ampollas tensas lineales, algunas de contenido hemático (figura 2). No se observaron lesiones en las mucosas.

Se tomó una biopsia de piel (Figura 3) y la inmunofluorescencia directa fue positiva para IgG en la membrana basal. Con estos hallazgos se confirmó el diagnóstico de liquen plano ampolloso y se inició prednisolona a dosis de $1 \mathrm{mg} /$ $\mathrm{kg} /$ día, con mejoría luego de tres semanas de tratamiento, sin recurrencia tres meses después (Figura 4).

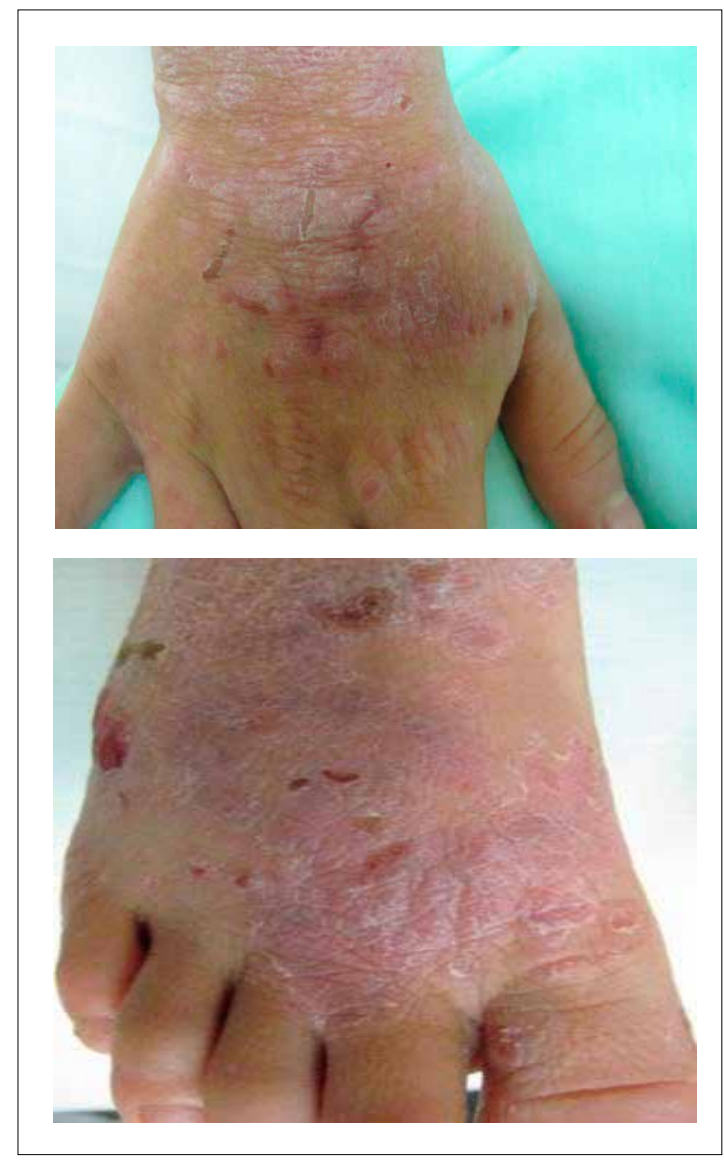

Figura1. Placas eritemato-violáceas conformadas por pápulas poligonales y brillantes, con descamación blanquecina en dorso de manos y pies. 


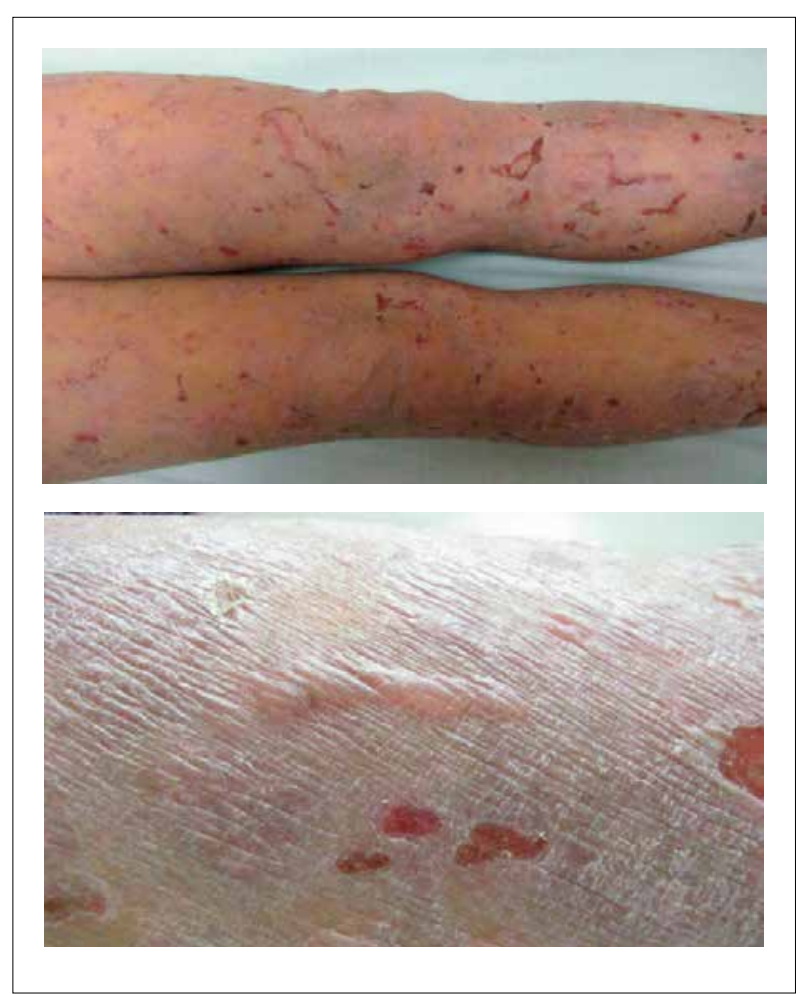

Figura 2. Varias ampollas tensas con distribución lineal, algunas de contenido hemático

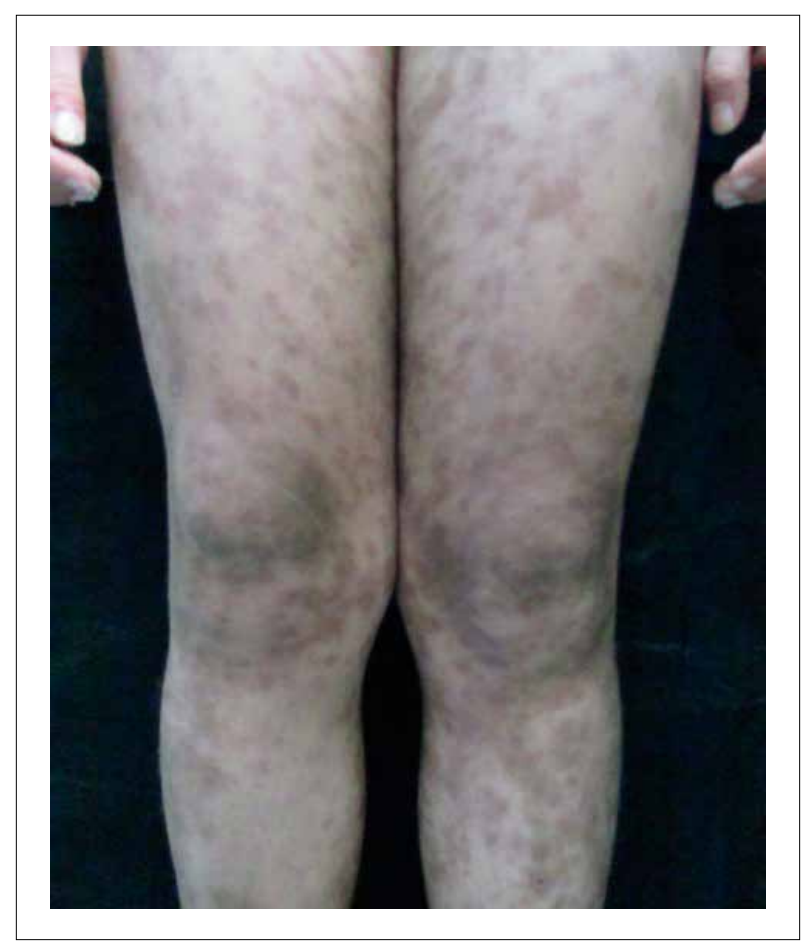

Figura 4. Hiperpigmentación residual después de tres semanas de tratamiento con prednisolona.

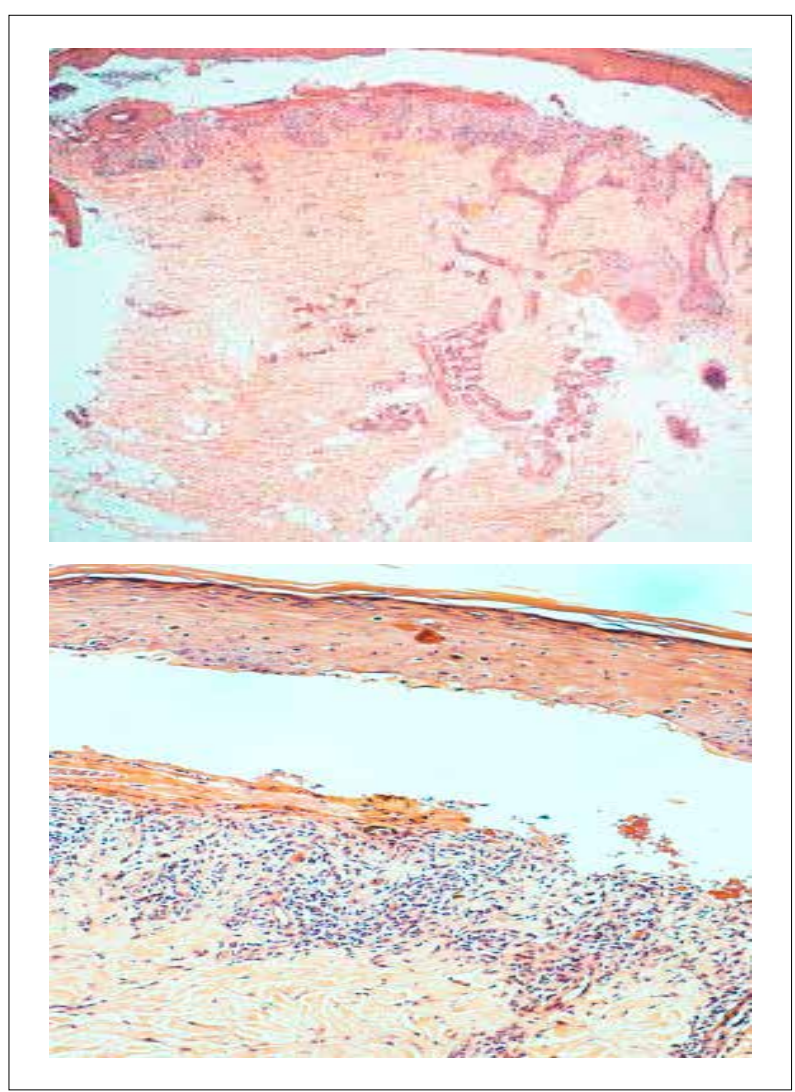

Figura 3. Hematoxilina y eosina $4 X$ y 10X.Dehiscencia dermo-epidérmica con formación de una ampolla, abundantes queratinocitos necróticos basales. Dermis con infiltrado linfocitario liquenoide rico en melanófagos.

\section{Discusión}

El liquen plano es una enfermedad inflamatoria idiopática mediada por linfocitos T (1). Es una erupción pápulo-escamosa que puede comprometer la piel, el cuero cabelludo, las uñas y las mucosas $(2,4)$. El término liquen plano fue introducido por primera vez en 1869 por Erasmus Wilson, para nombrar una condición que había sido descrita por Hebra como "leichenruber" (2). Viene del griego leichen que significa musgo y del latín planus que significa aplanado (3).

Aunque es más común en adultos, también se puede presentar en niños (4), como en el caso de nuestra paciente. Aunque su etiología y patogenia no están entendidas completamente, el liquen plano se ha asociado con múltiples enfermedades y factores etiológicos incluyendo infecciones virales, enfermedades autoinmunes, medicamentos y vacunas, entre otros (2). Los hallazgos clínicos típicos del liquen plano consisten en pequeñas pápulas poligonales violáceas, aplanadas, con estrías blancas reticulares en su superficie, 
conocidas como estrías de Wickham $(2,3)$. Sin embargo, se describen numerosas variantes en la presentación clínica según la configuración, el aspecto morfológico o la localización de las lesiones (3). Una de esas variantes, según el aspecto morfológico, es el liquen plano ampolloso (3).

Las ampollas afectan con mayor frecuencia las extremidades y se originan de pápulas de liquen plano, o rara vez, de piel de aspecto normal (3), y son el resultado de la licuefacción y vacuolización extrema de la capa basal $(5,6)$. Las ampollas pueden manifestarse bruscamente durante una exacerbación aguda de la enfermedad y, por lo general, se acompaña de síntomas sistémicos leves (3). Debido a la formación de ampollas, el diagnóstico diferencial incluye liquen plano penfigoide, penfigoide ampolloso, pénfigo vulgar, eritema multiforme e infección por virus del herpes $(2,7)$, entre otras enfermedades. Por lo tanto, el examen histopatológico es útil para el diagnóstico definitivo (7). Cuando ocurre en una zona localizada se debe diferenciar de la erupción fija por medicamentos (5). Histológicamente, se observan ampollas por separación dermo-epidérmi$\mathrm{ca}$, que se asocian a otros cambios de liquen plano (3). La inmunofluorescencia directa puede evidenciar depósitos globulares de IgM y, ocasionalmente, de IgG e IgA, con queratinocitos apoptóticos alrededor de la unión dermoepidérmica y en las capas inferiores de la epidermis (6), aunque en muchos casos puede ser negativa (8). El liquen plano ampolloso difiere del liquen plano penfigoide, en que en este último las ampollas aparecen comprometiendo la piel sana y en la histología se observa la ampolla sub-epidérmica, sin evidencia de otros hallazgos de liquen plano. Además, la inmunofluorescencia muestra depósitos lineales en la zona de membrana basal de IgG y C3 en la piel perilesional (8).

Para el tratamiento del liquen plano se utilizan esteroides tópicos y sistémicos, retinoides sistémicos, fototerapia PUVA, antimaláricos y agentes inmunosupresores como azatioprina y ciclosporina $(1,3)$. Nuestra paciente tuvo una adecuada respuesta al tratamiento con esteroides orales. Se informó un tratamiento efectivo del liquen plano ampolloso en una mujer adulta, con el esquema de esteroides en mini pulsos orales, además de betametasona dipropionato tópica en las lesiones de las mucosas (8). También se ha informado buenos resultados con micofenolato mofetil en esta variante ampollosa (1). No hay reportes en la literatura de tratamiento específico para liquen plano ampolloso en la edad pediátrica. Sin embargo por ser los esteroides orales el tratamiento de primera línea en el liquen plano clásico, consideramos realizar este manejo en nuestra paciente.

La resolución de las lesiones usualmente se acompaña de hiperpigmentación postinflamatoria. Las secuelas a largo plazo del liquen plano en la población pediátrica son raras (4).

\section{Conclusión}

La variante ampollosa es una presentación clínica poco frecuente del liquen plano, en la que se observan ampollas, además de las lesiones típicas de liquen. El diagnóstico se confirma mediante el estudio histopatológico y la inmunofluorescencia. El tratamiento con esteroides orales es efectivo y seguro en la edad pediátrica.

\section{Referencias}

1. Nousari H, Goyal S, Anhalt G. Successful treatment of resistant hypertrophic and bullous lichen planus with mycophenolatemofetil. Arch Dermatol.1999;135:1420-1.

2. Van Serooskerken AM, van Marion AM, de Zwart-Storm E, Frank J, Poblete-Gutiérrez P. Lichen planus with bullous manifestation on the lip. Int JDermatol. 2007;46:25-6.

3. Pittelkow M, Daoud M. Liquen plano. En: Dermatología en Medicina General Fitzpatrick. Wolff K, Goldsmith, Katz S, Gilchrest B, Paller A, Leffell D. 7 edición. Buenos Aires: Editorial panamericana; 2009.244-45.

4. Sharma A, Białynicki-Birula R, Schwartz RA, Janniger CK. Lichen planus: an update and review. Cutis.2012;90:17-23.

5. Karthikeyan K, Jeevankumar B, Thappa DM. Bullous lichen planus of the glans penis. Dermatol online J.2003;9:31.

6. Breathnach S, Lichen planus and lichenoid disorders. En: Rook`s Textbook of Dermatology. Burns T, Breathnach S, Cox N, Griffiths C. (eds). 7 ed. Oxford: Blackwell science, 2004.42.5.

7. Unsal B, Gültekin SE, Bal E, Tokman B. Bullous oral lichen planus: report of two cases. Chin Med J. 2003;116:1594-95.

8. Joshi A, Khaitan BK, Verma KK, Singh MK. Generalised and bullous lichen planus treated successfully with oral mini-pulse therapy. Indian J Dermatol Venereol Leprol. 1999; 65: 303-4. 